\title{
VALE-PRESENTE: COMO FICA A DIMENSÃO SIMBÓLICA DO ATO DE
}

\section{PRESENTEAR?}

\author{
Cléria Donizete da Silva Lourenço \\ Doutorado em Administração pela UFL \\ Departamento de Administração e Economia - DAE \\ cleria@dae.ufla.br \\ Daniel Carvalho de Rezende \\ Pós-doutorado em Marketing - Lancaster University \\ Departamento de Administração e Economia - DAE \\ danielderezende@dae.ufla.br
}

Recebido em 08/dezembro/2010

Aprovado em 18/setembro/2012

\section{RESUMO}

Verificando o surgimento de um novo formato de presentear - o vale-presente -, buscou-se resposta para a seguinte pergunta de pesquisa: a crescente utilização do vale-presente indica uma tendência de redução do simbolismo do ato de presentear? A metodologia utilizada foi a grounded theory, por meio de entrevistas com 17 pessoas em duas cidades do interior de Minas Gerais. Como resultado de pesquisa, foram extraídas as seguintes categorias: um presente que é a sua cara, a reciprocidade, o simbólico por excelência, o senhor e o escravo, o vale-presente. Os resultados evidenciam que o ato de presentear, mesmo com a crescente utilização do vale-presente, continua sendo um ato predominantemente simbólico. O vale-presente, apesar de não ter boa aceitação entre a maioria dos entrevistados, foi considerado apropriado para determinados contextos. Os resultados contribuem com elementos teóricos da antropologia para um melhor entendimento do comportamento de presentear.

Palavras-chave: Vale-presente. Simbolismo. Comportamento do consumidor.

\section{ABSTRACT}

Nowadays, we can identify the coming out of a new way to give a gift - the bonus-gift, and this work have sought to answer the following question: Does the increasing of gift-bonus approach indicates a trend of symbolism reduction of the act to give a gift? The methodological approach was qualitative, making use of the grounded theory, and data collection comprised of interviews with 17 people in two cities of Minas Gerais countryside. As a result of the investigation the following categories were identified: A gift that was made for you; Reciprocity; The symbol by excellence; The lord and the slave; The gift-bonus. The results have shown that the act to give a present, even with the growing of gift-bonus, remains predominantly a symbolic ritual. The gift-bonus does not have a good acceptance among the majority of respondents, but was considered appropriate in certain contexts. The results contribute to the theoretical elements of anthropology to a better understanding of gift giving behavior.

Key words: Gift bonus, Symbolism, Consumer behavior. 


\section{INTRODUÇÃo}

A compra de presentes é responsável por grande parte do volume de vendas no varejo. Conforme informam Pépece, Marchetti e Prado (2001), o volume de vendas representado pelas compras para presentes, em diversas categorias do varejo, como roupas, calçados, cosméticos, flores, entre outras, supera os $50 \%$ das vendas totais, uma vez que se consideram esses produtos de utilização frequente nesse tipo de consumo.

Apesar da compreensão de que o ato de presentear é algo que ultrapassa os limites da racionalidade (LARSEN; WATSON, 2001), é possível entender, em algum nível, o comportamento de presentear dos compradores. Considera-se, ainda, que a pesquisa sobre a maneira como se presenteia pode ser relevante para o estudo do comportamento do consumidor e, consequentemente, para os varejistas, pois a partir dela podem-se entender vários fatores que levam o comprador a se comportar de determinada maneira. Conforme Sherry (1983), estudar a prática de presentear é importante, tanto pelo seu valor representativo na economia quanto pela representatividade de seu papel em criar e manter relacionamentos, dado que os presentes são expressões tangíveis desses relacionamentos. No Brasil, algumas pesquisas, como a de Farias et al. (2001), Pépece (2002), Santana, Carvalho e Fagundes (2006) e Almeida e Lima (2007), procuraram compreender o ato de presentear no País.

$\mathrm{O}$ ato de presentear, tradicionalmente, é tido como predominantemente simbólico. Nos últimos tempos, porém, na sociedade ocidental, tem surgido uma nova forma de se dar presentes - o vale-presente -, ou seja, presentear com dinheiro. O vale-presente, segundo Atbay (1993), desmistifica uma regra de etiqueta: a de não se poder revelar o valor do presente. Para Bourdieu (1996), se se quiser eliminar o aspecto simbólico do presente, basta, em vez de comprar, pesquisar e descobrir do que a pessoa gosta, preencher um cheque e entregá-lo a ela. Assim, perdem-se a magia e o ritual.

Neste trabalho, especificamente, trata-se da questão dentro do contexto da civilização ocidental, em que o vale-presente surgiu há pouco tempo como alternativa de economia de tempo e minimização do risco envolvido com o ato de presentear (SMART, 1993). Convém, entretanto, reconhecer e destacar que o presente em dinheiro é tradicional em certas culturas, como a chinesa.
Existe, no Ano-novo chinês, um ritual de presentear crianças e amigos com dinheiro colocado em envelopes vermelhos. Também é comum, nos casamentos chineses, se presentear com dinheiro, geralmente com valores já previamente estabelecidos no âmbito social.

Segundo o Portal Varejista (2004), o vale-presente no Brasil ainda não é tão popular quanto nos Estados Unidos, onde se estima que essa forma de presentear seja responsável pela movimentação de 1,8\% do total do mercado varejista. A mídia televisiva, entretanto, destacou nos seus noticiários sobre as compras de fim de ano, ao final de 2007, a crescente utilização dessa alternativa, o que também justifica a pesquisa sobre o tema.

A literatura sobre $o$ ato de presentear evidencia que a dimensão predominante é a simbólica, tanto na antropologia quanto no marketing. Contudo, diante do surgimento do vale-presente, que poderia ser considerado em uma dimensão utilitarista, cabe investigar os temas: $\mathrm{o}$ ato de presentear ainda carrega preponderantemente dimensões simbólicas? A crescente utilização do valepresente indica uma tendência de redução do simbolismo do ato de presentear?

Essas questões orientam esta pesquisa, que tem como objetivo principal conhecer o que o consumidor tem a dizer a respeito de suas experiências de dar e receber presentes. A metodologia utilizada foi a grounded theory, proposta por Glaser e Strauss (1967), que tem como princípios: identificação de uma área e coleta de dados, interpretação dos dados iniciais, posterior coleta de dados, amostragem teórica (processo que facilita a extração das categorias) e desenvolvimento de conceitos e categorias (geração da teoria).

Este artigo está estruturado em seis seções. A primeira seção constitui-se desta introdução. Na segunda, procurou-se delinear a fundamentação teórica por meio da compreensão da dimensão simbólica do ato de presentear e do vale-presente; na terceira seção, são apontados os procedimentos metodológicos da pesquisa; na quarta, apresentam-se e discutem-se os resultados e, por fim, na quinta seção, são feitas as considerações finais.

\section{Ato De Presentear}

A ação de presentear tem sido relatada desde os tempos pré-históricos, o que mostra ser algo enraizado nos costumes de toda a humanidade. Essa prática 
universal (MAUSS, 2003; SCHWARTZ, 1967) tem sido extensivamente explorada por pesquisadores de diversas disciplinas tais como a sociologia (GOULDNER, 1960), a antropologia (COELHO, 2006; MAUSS, 2003), a psicologia (SCHWARTZ, 1967) e o marketing (BELK, 1979; BELK; COON, 1993; LARSEN; WATSON, 2001; QIAN; RAZZAQUE; KENG, 2007; SHERRY, 1983; SHERRY; MCGRATH, 1989; WOLFINBARGER, 1990).

O ato de presentear é definido por Macklin e Walker (1988) como a avaliação, a seleção e a transferência de objetos tangíveis e intangíveis de uma maneira espontânea ou em cumprimento de uma obrigação. Contudo, usualmente o ato de presentear tende a ser simbólico. Dada essa dimensão, buscou-se contribuição na antropologia, especialmente por meio da teoria da dádiva, para compreender o simbolismo da prática.

\subsection{ATO DE PRESENTEAR - DIMENSÃo SIMBÓLICA}

Na perspectiva da dádiva, o ato de presentear é eminentemente simbólico. Mauss, (2003) em seu Ensaio sobre a dádiva ${ }^{1}$, definia a dádiva de modo bastante amplo. Nas sociedades tradicionais, "as trocas e os contratos se fazem sob a forma de presentes, em teoria voluntários, na verdade obrigatoriamente dados e retribuídos” (p. 187). Assim, uma característica essencial da dádiva, segundo Mauss, é que ela não se reduz a um ato obrigatório isolado: as obrigações de dar, de receber e de retribuir constituem os “três temas do mesmo complexo" (p. 201). Portanto, a obrigação de dar é acompanhada sempre de duas outras, receber e retribuir. "Recusar dar, negligenciar conviver, assim como recusar receber, equivale a declarar guerra; é recusar a aliança e a comunhão” (p. 201-202).

Nessa perspectiva, o que é essencial à dádiva é seu “valor de ligação” ou, conforme expressão de Godbout (1999, p. 200), seu “valor de vínculo”. Para esse autor, a dádiva é "qualquer prestação de bem ou de serviço, sem garantia de retorno, com vistas a criar, alimentar ou recriar os vínculos sociais entre as pessoas” (p. 29). Portanto, na perspectiva da dádiva, as pessoas trocam presentes para iniciar, manter ou retomar relacionamentos. Mauss (2003), contudo, afirma a existência de "duas verdades" na dádiva: seu caráter "voluntário”, expresso na "teoria”, e a "obrigação" da retribuição, presente na "realidade" da dádiva. Assim, a dádiva repousa em um princípio de liberdade e de obrigação estreitamente misturadas.

Entre as três obrigações - dar, receber e retribuir - a que mais intrigou Mauss (2003) foi a obrigação de retribuir. Portanto, o grande questionamento feito por ele foi: "qual é a regra de direito e de interesse que (...) faz que o presente seja obrigatoriamente retribuído?” (p. 188); “que força leva a retribuir uma coisa recebida?” (p. 193). Ele procurou, então, entender a razão da obrigação de retribuir o presente recebido.

Mauss (2003) concluiu que oferecer alguma coisa a alguém significa oferecer alguma coisa de si, e “aceitar alguma coisa de alguém é aceitar algo de sua essência espiritual, de sua alma” (p. 200). É nesse aspecto que se encontra o porquê da retribuição. Para ele, "se o presente recebido, trocado, obriga, é que a coisa recebida não é inerte” (p. 198), ou seja, as coisas têm uma força. Nessa perspectiva, as coisas jamais se separam completamente de quem as troca; a comunhão e a aliança que elas estabelecem são relativamente indissolúveis. Portanto, a razão da retribuição está no vínculo que o recebedor estabeleceu ao aceitar o presente do doador: se aceitar a dádiva, "a pessoa sabe que se compromete” (MAUSS, 2003, p. 248), ou seja, ao aceitar o presente, a pessoa se compromete com aquele relacionamento.

Para Coelho (2006), se o sentido último do presente é uma proposta de estabelecimento de um vínculo entre o doador e o donatário, seu significado só se concretiza na reação do donatário, ou seja, na aceitação e na retribuição do presente. Godbout (1999), entretanto, afirma que os atores não mencionam para seus interlocutores o "dever da reciprocidade” para deixá-los o mais livre possível para retribuir ou não.

A reciprocidade, contudo, desempenha um papel fundamental porque a "troca de dádivas é governada pela norma da reciprocidade” (SCHWARTZ, 1967, p. 8). Godbout (1999) destaca que as pessoas afirmam a ausência de espera de retorno, mas esperam que o presente seja retribuído, ou seja, “alardeia-se a dádiva, mas fica-se na reciprocidade” (p. 215).

Nessa concepção, o ato de presentear é um ato governado pela "regra do implícito” (BOURDIEU, 1996, p. 168). Um aspecto que evidencia essa regra é o fato de não ser conveniente mencionar o preço no presente. Isso porque o importante não é verdadeiramente o valor do presente, mas a intenção, o rito reconhecido. Para 
Bourdieu (1996), se se quiser eliminar o aspecto simbólico do presente, basta, em vez de dar um presente, comprar, pesquisar, descobrir do que a pessoa gosta, preencher um cheque e entregá-lo a ela. Assim, perdem-se a magia e o ritual. Nesse caso, como ficaria a questão da identidade mencionada na literatura sobre o ato de presentear?

Para Schwartz (1967), a oferta de um presente é uma "imposição de identidade", sendo uma das formas pelas quais as imagens que os outros fazem de nós em sua mente são transmitidas. Na concepção desse autor, os presentes revelam um segredo importante: a ideia que o receptor evoca na imaginação do doador. Sobre esse aspecto, Coelho (2006) apresenta exemplos de troca de presentes nos quais o doador, ao ofertar um objeto inadequado para uso pelo receptor, expressa uma visão equivocada a seu respeito. Assim, a conhecida expressão “um presente que é a sua cara” (COELHO, 2006, p. 35), dita por um doador, pode não ser sempre condizente com a percepção do receptor.

A oferta de um presente como uma "imposição de identidade” não é uma perspectiva presente somente na psicologia (SCHWARTZ, 1967) ou na antropologia (COELHO, 2006), mas também na literatura de marketing. Wolfinbarger e Gilly (1996, p. 458) ressaltam que "os objetos que se tornam presentes transcendem suas funções puramente econômicas para se tornarem representativos e extensões do próprio doador e receptor”. Sherry e McGrath (1989) verificaram que os consumidores geralmente baseiam suas decisões de compra de presentes na sua própria imagem. Ao selecionar um presente específico, o doador demonstra familiaridade com as preferências do receptor. Os presentes relacionados ao receptor não são convencionais, ao contrário, apresentam características singulares.

Segundo Belk e Coon (1993), as pessoas dão presentes porque querem expressar sentimentos. Nessa lógica, os presentes são importantes porque são expressões do eu do presenteador e de seus sentimentos mais pessoais. Evidências empíricas nesse sentido são encontradas no trabalho de Farias et al. (2001), demonstrando que o significado do ato de presentear está relacionado a uma demonstração de carinho, amor e atenção, e revelando aspectos das dimensões simbólicas e emocionais do comportamento de presentear. Além disso, dar presente se insere no ato maior de se relacionar e pertencer a uma família, um grupo ou uma comunidade (TRENTMANN, 2009).

O significado do presentear pode também estar relacionado a motivações como a obrigação. Conforme Wolfinbarger (1990), a atitude de presentear por obrigação é motivada pela concordância com as normas sociais. Para o autor, aqueles que se sentem obrigados a presentear experimentam um sentimento de culpa se não o fazem e presenteiam simplesmente para atender às expectativas dos outros, sentindo-se no dever de retribuir um presente recebido. Contudo, no Brasil, de acordo com os resultados da pesquisa de Farias et al. (2001), parece que as pessoas não imaginam que dar presentes possa ser uma imposição. Somente 3\% dos participantes comentaram algo sobre a obrigatoriedade do ato de presentear.

Money (2007) menciona outros tipos de obrigação vinculados ao presentear, como o sentimento que leva o receptor a exibir o presente de modo visível ao presenteador. A exposição de objetos de decoração ganhos de outros membros da família em uma casa é citada como exemplo desse comportamento.

Pépece (2002) comenta que um dos principais influenciadores do ato de presentear é o grau de ligação existente entre o presenteador e o receptor. As pessoas costumam presentear com maior frequência indivíduos com os quais tenham grande ligação afetiva, notadamente pessoas da família. Dessa maneira, Belk (1979) destaca que, em média, somente um terço de todos os presentes dados por uma pessoa envolve indivíduos que não pertencem à família. Esse autor ainda cita que os presenteadores compram com mais prazer presentes destinados a pessoas com as quais têm uma relação de amizade.

Belk (1979, p. 18) afirma que "os presentes não são tão sagrados quanto as conexões que eles simbolizam entre as pessoas”. Portanto, o ato de presentear, um ritual considerado relaxante e prazeroso, pode ser também torturante. Um estudo realizado por Wooten (2000) apontou que as pessoas ficam ansiosas quando estão altamente motivadas a induzir as reações desejadas dos receptores e de outros, mas estão em dúvida se terão sucesso. Além disso, a ansiedade depende das características dos receptores, da situação e da própria pessoa. Assim, conforme apontaram Larsen e Watson (2001), a ação de presentear é envolvida pelo custo do 
presente, pelo contexto no qual tanto o presenteador quanto o presenteado estão inseridos e pela adequabilidade do presente.

$\mathrm{O}$ ato de presentear como um ritual torturante pode ser analisado também a partir do posicionamento magister e minister discutido por Hayden (1987, citado por Silva, Cerchiaro e Mascetti, 2004). Nessa ótica, a atitude aponta claramente para o exercício do poder por meio dos posicionamentos magister (o senhor, o doador) e minister (o escravo, o devedor). Em poucas situações o presenteado não se sente devedor do presenteador. Isso ocorre porque o benefício e a recompensa proporcionados pelo presente em si tanto validam a subserviência do presenteado e sua consequente deferência em relação ao presenteador quanto caracterizam a intensidade, o tamanho e o grau de importância da dívida do receptor. Na pesquisa de Silva, Cerchiaro e Mascetti (2004), os entrevistados relataram preferir presentear a ser presenteados, principalmente quando o presente é caro ou luxuoso. Os autores ressaltam que, em geral, as pessoas não gostam de se sentir devedoras, preferindo adotar o papel de magister do que o de minister.

\subsection{O VALE-PRESENTE}

Um ponto que está se tornando muito pertinente para a análise na área de marketing é a escolha de presentear com dinheiro, equivalente ao vale-presente, conforme discutido por Santana, Carvalho e Fagundes (2006).

O vale-presente poderia ser considerado uma dimensão utilitarista do ato de presentear, relacionada à conveniência e ao valor financeiro. Uma pessoa pode escolher o presente devido à conveniência da compra ou ainda pode preferir produtos que sejam mais baratos. Assim, há uma economia de tempo e dinheiro. Por exemplo: o indivíduo pode preferir dar um vale-presente devido à facilidade de eliminar algumas etapas do ato de presentear, ou seja, com o vale-presente ele não precisa avaliar e nem selecionar o presente, apenas entregar ao receptor. Com isso economiza tempo e esforço.

Nos Estados Unidos, um recorde de 61\% dos consumidores deram vale-presente em 2007, quase o dobro dos 32\% do ano de 2006 (PORTAL EXAME, 2007). Mas, segundo o Portal Varejista (2004), o vale-presente no Brasil ainda não é tão popular quanto nos Estados Unidos, onde se estima que essa forma de presentear seja responsável pela movimentação de 1,8\% do total do mercado varejista. A mídia televisiva, entretanto, destacou nos seus noticiários sobre as compras de fim de ano, ao final de 2007, a crescente utilização dessa alternativa. Várias empresas aderiram ao vale-presente: Pernambucanas, Submarino, Americanas, Ponto Frio, Lojas Renner, Sack’s Perfumaria, diversas livrarias e lojas de cds, restaurantes, cinemas, supermercados, lavanderias, entre outras (PORTAL EXAME, 2007). Na maioria dessas lojas, o vale-presente se apresenta na forma de um cartão magnético, que contém créditos (valor) para troca na loja.

O vale-presente, segundo Atbay (1993), desmistifica uma regra de etiqueta presente em várias sociedades que diz não se poder revelar o valor do presente, apesar de a alternativa ser mais sentimental e ingênuo que entregar o dinheiro per se. Contudo, ainda segundo a citada autora, os tradicionalistas sustentam sua posição de que dar dinheiro, não importa qual seja a forma, representa falta de intimidade e de imaginação.

O vale-presente pode ser conceituado como um formato de presente disponibilizado por lojas, geralmente simbolizado em um cartão, que oferece ao presenteado a oportunidade do escolher o seu próprio presente, descontando do valor a ser pago por ele a quantia representada pelo vale-presente - quantia essa estipulada pelo presenteador, no ato da compra. O vale-presente é uma forma disfarçada de se ofertar dinheiro na ação de presentear. Algumas das razões apontadas por Atbay (1993) para a compra desse produto são a conveniência, a adequação, a atratividade e a flexibilidade de troca. Podese acrescentar a esses fatores a redução do risco de se errar e escolher um presente inadequado.

Para os varejistas brasileiros, a praticidade é o maior trunfo do vale-presente. É comum usá-lo quando não se conhece a fundo as preferências do outro e é uma boa ideia para quem não sabe ou não tem tempo para escolher o presente. Mas alguns varejistas reconhecem que, para a grande maioria dos brasileiros, o recurso é impessoal, chega a ser deselegante e pode passar uma imagem de desinteresse pelo outro (PORTAL VAREJISTA, 2008).

No Brasil, um trabalho importante que trata do valepresente é o de Santana, Carvalho e Fagundes (2006). Os autores concluíram que a maioria das pessoas está mais propensa a considerar o vale-presente como uma 
opção interessante de compra quando os presenteados são pessoas “difíceis” de agradar, o que aumenta o risco incorrido pelo doador. Assim, conforme pontuaram Otnes, Lowrey e Kim (1993), o fato de o receptor ser considerado fácil ou difícil de ser agradado pode ser determinante na escolha do presente.

A revisão de literatura sobre o ato de presentear evidencia que a dimensão simbólica é predominante, tanto na antropologia quanto no marketing. Contudo, diante do surgimento do vale-presente, que poderia ser considerado em uma dimensão utilitarista, cabe fazer a seguinte pergunta: o ato de presentear ainda carrega predominantemente dimensões simbólicas? Antes, porém, de discutir essa questão, são apresentados os procedimentos metodológicos da pesquisa.

\section{Metodologia - Grounded Theori}

O método de pesquisa escolhido foi a grounded theory, traduzida em português como teoria fundamentada nos dados. O termo grounded é utilizado para reforçar a ideia de que a teoria ${ }^{2}$ é construída a partir de comportamentos, palavras e ações daqueles que estão sendo pesquisados (GOULDING, 2002).

Glaser e Strauss (1967) procuraram conceber um método de pesquisa em que o pesquisador, ao invés de "forçar" pressuposições ou categorias/conceitos teóricos pré-existentes, ou seja, de tomar a teoria como ponto de partida, deveria procurar conceber uma teoria fundamentada em dados representativos da "realidade" dos sujeitos estudados. A ideia, nesse caso, é começar a pesquisa não com a definição de uma estrutura teórica analítica, mas sim com um problema geral concebido apenas em termos de perspectivas disciplinares mais amplas (DEY, 1999). Essa área substantiva de pesquisa seria suficiente como ponto de partida para que o pesquisador decida o que e onde estudar. Uma vez tendo identificado o problema - definido em termos gerais - e selecionado o lugar onde esse problema pode ser estudado, o pesquisador deve permitir que as evidências, as quais aos poucos vão emergindo e se somando, ditem a sua agenda de pesquisa (DEY, 1999).

O método proposto por Glaser e Strauss (1967) baseiase nos seguintes princípios: identificação de uma área e coleta de dados (neste caso, o presentear), interpretação dos dados iniciais e posterior coleta de dados, amostragem teórica (processo que facilita a extração das categorias) e desenvolvimento de conceitos e categorias (geração da teoria). Assim, a grounded theory é uma metodologia fundamentada nos dados sistematicamente coletados e analisados. A teoria evolui durante o processo e é produto da análise dos dados. Isso quer dizer que o pesquisador é direcionado para a literatura que melhor se adequa ao fenômeno estudado e o explica (GOULDING, 2001).

Nosso interesse, nesta pesquisa, coaduna-se com a ideia de Charmaz (2006, p. 46) ao afirmar que "saber o que acontece na vida das pessoas (...) entender os pontos de vista, as situações e as ações delas dentro de um contexto, de um cenário específico”, neste caso, a ação de presentear. Portanto, os procedimentos foram os seguintes:

- Identificação do problema, definido em termos gerais: a crescente utilização do vale-presente indica uma tendência de redução do simbolismo do ato de presentear? Com a delimitação da pergunta de pesquisa, estabeleceuse o seguinte objetivo: conhecer o que o consumidor tem a dizer a respeito de suas experiências de dar e receber presentes.

- Definição do local de realização da pesquisa: as cidades de Lavras e Nepomuceno, localizadas ao Sul de Minas Gerais.

- Escolha dos informantes: homens e mulheres, pertencentes às classes econômicas $\mathrm{A}$ e $\mathrm{B}$, com renda própria, o que os colocam, teoricamente, em condições financeiras de presentear.

- $\quad$ Elaboração de um roteiro semiestruturado para instrumento de coleta de dados. Os tópicos abordados referiram-se a situações vividas pelos entrevistados ao darem e receberem presentes. Foram reveladas ocorrências de experiências agradáveis e desagradáveis e identificadas situações julgadas marcantes ou inesquecíveis. O roteiro trazia ainda uma parte em que os entrevistados eram estimulados a falar sobre a história de um presente marcante em suas vidas. Um ponto central do roteiro de entrevistas foi o questionamento sobre a opinião dos participantes sobre dar e receber vale-presentes.

- Realização das entrevistas em profundidade: realizaram-se entrevistas com 8 homens e 9 mulheres, em uma faixa etária entre 22 e 42 anos, entre outubro de 2007 e janeiro de 2008. Todas as entrevistas foram gravadas e em seguida transcritas e analisadas concomitantemente. 
Tomaram-se também algumas notas durante as entrevistas.

- Amostragem teórica: aspectos simbólicos do ato de presentear encontrados na antropologia (mais especificamente na teoria da dádiva) e na área de comportamento do consumidor auxiliaram na dedução de categorias específicas.

- Posterior coleta de dados: com ideias teóricas iniciais "em mãos", voltou-se ao campo para verificar como elas se relacionavam com um novo conjunto de material empírico (CHARMAZ, 2006). Por exemplo, o tema da reciprocidade [retribuição do presente recebido] apareceu de forma significativa nas primeiras entrevistas. Por isso, depois da amostragem teórica, procurou-se explorar esse tema na segunda ida ao campo, perguntando aos entrevistados se e por que eles retribuem os presentes recebidos.

- $\quad$ Análise e interpretação final dos dados.

A transcrição de cada entrevista permitiu a análise dos conteúdos encontrados e a identificação das principais palavras e frases que caracterizam as categorias encontradas. As observações feitas durante as entrevistas também foram consideradas. A partir disso, operou-se a codificação dos dados. Inicialmente foi feita a desconstrução das entrevistas, partindo-as em blocos de informação, e em seguida foram "garimpados" códigos abertos que descrevem as diferentes unidades de significado e semelhanças entre as entrevistas. Finalmente, estabeleceu-se uma conexão entre os temas e conceitos que "brotaram" desse cruzamento de informações na forma de categorias analíticas (GOULDING, 2002), categorias essas (iniciais e emergentes) que representam uma explicação das inter-relações dinâmicas do fenômeno estudado, constituindo, portanto, a base de uma teoria "garimpada” (Grounded Theory). Vale destacar que, como o presente estudo foi realizado por dois pesquisadores, o processo de análise passou por um procedimento de codificação e interpretação consensual.

É importante destacar que uma teoria fundamentada não é sempre e necessariamente construída apenas com base nos dados coletados. Caso haja referências teóricas que pareçam ser adequadas para o fenômeno sob investigação, elas podem e devem ser utilizadas, refinadas, modificadas e adaptadas por meio da justa (ou contra) posição das observações feitas no campo
(STRAUSS; CORBIN, 1998), o que ocorreu nesta pesquisa. Após a primeira coleta de dados, verificou-se que havia, na literatura, referências teóricas consistentes (teoria da dádiva e comportamento de presentear) para explicar o comportamento dos entrevistados.

\section{Análises E Resultados}

Durante o processo de coleta de dados, foram realizadas dezessete entrevistas em profundidade. A identificação dos respondentes é dada conforme o Quadro 1.

Quadro 1 - Caracterização dos respondentes

\begin{tabular}{|c|c|c|c|c|}
\hline Identificação & Sexo & Idade & Profissão & Estado Civil \\
\hline E1 & M & 33 & Prof. Universitário & Casado \\
\hline E2 & F & 25 & Profa. Universitáría & Solteira \\
\hline E3 & M & 29 & Diretor executivo de comércio & Solteiro \\
\hline E4 & F & 35 & Profa. Universitária & Viúva \\
\hline E5 & M & 22 & Vendedor & Solteiro \\
\hline E6 & F & 42 & Funcionária Pública & Casada \\
\hline E7 & M & 33 & Corretor de seguro & Casado \\
\hline E8 & F & 35 & Gerente administrtativo & Casada \\
\hline E9 & F & 30 & Empresária & Solteira \\
\hline E10 & M & 32 & Funcionário público & Casado \\
\hline E11 & F & 29 & Empresária & Casada \\
\hline E12 & M & 39 & Construtor & Casad0 \\
\hline E13 & F & 33 & Gerente de estágio & Casada \\
\hline E14 & F & 34 & Secretária administrativa & Casada \\
\hline E15 & M & 40 & Bancário & Casado \\
\hline E16 & M & 32 & Vendedor & Casado \\
\hline E17 & F & 28 & Publicitáría & Solteira \\
\hline
\end{tabular}

Fonte: Dados da pesquisa.

Por meio da grounded, buscou-se observar e entender o comportamento das pessoas pelo ponto de vista delas, aprendendo sobre seu mundo, sobre a interpretação que elas fazem de si no contexto de uma dada interação como forma de explorar os significados e as explicações atribuídas às suas experiências de presentear.

Frases como: "gosto mais de dar do que de receber" (E9); “gosto mais de receber do que de dar” (E12); “é interessante tanto dar quanto receber" (E5); "gosto muito (...) principalmente porque eu preciso retribuir" (E6); “não gosto, não sinto prazer, só dou quando é estritamente necessário” (E1); “se eu pudesse não daria 
presente nunca” (E10); "não me sinto à vontade em receber, mas gosto de dar" (E3), obtidas como respostas para o questionamento sobre o aspecto de gostar de dar e receber presentes, por si só, já demonstram quão complexo é o comportamento das pessoas no que se refere ao ato de presentear.

Algumas pessoas sentem grande prazer em presentear, outras se sentem angustiadas quando precisam fazê-lo (E16, por exemplo), outras ainda somente presenteiam porque se sentem “obrigadas”, enfim, as pessoas assumem o comportamento de presentear por diversos motivos. Contudo, é possível encontrar algumas características comuns aos entrevistados.

Os entrevistados trocam, mais assiduamente, presentes com pessoas com as quais mantêm grande proximidade afetiva, tais como esposo(a), namorado(a), filhos, pais, irmãos, avós e amigos íntimos. Raras trocas de presentes são feitas com pessoas fora desse círculo familiar e afetivo, o que reforça a conclusão de Pépece (2002) de que as pessoas costumam presentear com maior frequência indivíduos com os quais tenham grande ligação afetiva, principalmente da família. Um dos principais influenciadores do ato de presentear, portanto, é o grau de ligação existente entre o presenteador e o receptor. Observou-se, ainda, que os presenteadores sentem maior prazer em comprar presentes para as pessoas que lhes são próximas, aspecto já observado por Belk (1979). Quando se tratava de pessoas fora do círculo afetivo, como por exemplo, colegas de trabalho, os entrevistados não demonstraram muito entusiasmo.

Outra característica comum é bastante reveladora. Embora existam, no Brasil, ocasiões comemorativas como Natal, aniversário, dia das mães, dia dos pais, dia dos namorados, entre outras, nas quais comumente as pessoas trocam presentes, o fator surpresa apareceu com grande intensidade nas falas dos entrevistados. Muitos disseram que gostam mais de receber presente em um dia comum, ou seja, fora das ocasiões especiais. Os entrevistados relataram situações cotidianas nas quais esse tipo de presente revela cuidado e carinho. Essas evidências são condizentes com a afirmação de Farias et al. (2001) de que o significado do ato de presentear está relacionado a uma demonstração de carinho, amor e atenção, revelando aspectos das dimensões simbólicas e emocionais do comportamento de presentear.

\subsection{Categorias EMERgentes E Discussão}

Entre os temas que compunham o roteiro de entrevista, havia uma solicitação para que os entrevistados relatassem histórias de presentes marcantes, dados ou recebidos, agradáveis ou desagradáveis. Com base na análise e interpretação dessas histórias e de outras questões respondidas, foram delineadas algumas categorias sobre o ato de presentear: um presente que é a sua cara; a reciprocidade; o simbólico por excelência; o senhor e o escravo; o vale-presente. Assim, as categorias apresentadas a seguir emergiram espontaneamente nas entrevistas feitas durante a pesquisa e foram nomeadas com conceitos encontrados na teoria. As palavras em itálico, nos relatos de entrevistas transcritos no texto, representam os pontos destacados pelos entrevistados.

\section{UM PRESENTE QUE É A SUA CARA}

DAR PRESENTES É UMA COISA QUE ME INSTIGA BASTANTE

(...) PROCURAR AS COISAS PRA AGRADAR AS PESSOAS MESMO, NÉ... COMPRAR UM PRESENTE COM A CARA DA PESSOA... (E2).

Procuro pensar o tipo de Personalidade da Pessoa E DAR ALGO ASSIM QUE VAI AGRADAR. Às VEZES, A GENTE OLHA NA VITRINE E ACHA ALGUMA COISA QUE É CARA DA FULANA, A CARA DA BELTRANA... (E6).

Frases como "um presente com a cara da pessoa", várias vezes citadas em diversas entrevistas, fazem dessa categoria a principal representante do comportamento de presentear. As pessoas querem dar um presente que agrade e esse agradar parece estar relacionado a ofertar um presente que esteja de acordo com as características do presenteado, ou seja, "um presente com a cara dele”. Portanto, a investigação empreendida nesta pesquisa por meio da grounded theory trouxe à tona a teoria da dádiva uma teoria que explica as trocas nas sociedades tradicionais e que tem Marcel Mauss como seu representante. Assim, essa teoria constituiu a melhor explicação teórica para o comportamento de presentear.

Entre os relatos sobre os presentes marcantes, uma história se destacou devido à indignação e à intensa lembrança por parte da entrevistada. Apesar de passados muitos anos, ela conta a história com detalhes. 
... DESSE PRESENTE EU ME LEMBRo! Eu TAVA NA 6 a SÉRIE E NAQUEla ÉPOCA EU TINHA O CABELO BATIDO QUE SÓ SE PENTEAVA COM OS Dedos. Aí, Eu GANHei um PENTE, uma ESCOVA E um espelho. Eu DETESTEi! A PESSOA NÃo PENSOU EM MIM PRA COMPRAR, NÉ? SE ElA TIVESSE ANALISADO UM POUQUINHO ELA PODERIA TER ME DADO ATÉ UM GEL PARA PASSAR NO CABELO, MAS UM PENTE?... ESSE EU NUNCA VOU ESQUECER... (E6).

Outros entrevistados falam de suas decepções com os presentes recebidos. Embora fossem considerados, por alguns, como bons presentes [bons no sentido de caro], eles evidenciam a falta de conhecimento dos presenteadores sobre os gostos dos presenteados.

MEU NAMORADO ME DÁ PRESENTES RELACIONADOS À

TECNOLOGIA: MP3, CELULAR SOFISTICADO... MAS EU NÃO SOU LIGADA NESSAS COISAS. ELE QUER DAR PRESENTES CAROS, BONS, MAS NÃO É ISSO QUE EU GOSTO DE GANHAR (E9).

Eu GOSTO É DE GANHAR ROUPAS, EU ADORO GANHAR ROUPA, MAS AS PESSOAS, ÀS VEZES, NÃO SABEM DISSO. EU GANHEI UMA BOLSA CARÍSSIMA NO MEU ANIVERSÁRIO (VICTOR HUGO, QUASE 400,00), A BOLSA TÁ LÁ, PRETA... ALÇA DOURADA... MAS EU PREFERIA COISA PRA USAR NO DIA A DIA, NÉ? (E2).

... NO AMIGO OCULTO DA EMPRESA, NO FINAL DO ANO, EU RECEBI UMA CALÇA HORRÍVEL: DE CÓS ALTO, COM LYCRA E NA COR AZUL ESCURO. EU ODIEI, EU NÃO GOSTO DE CÓS ALTO, NÃO USO CALÇA COM LYCRA E NÃO GOSTO DE AZUL ESCURO, OU SEJA, EU DETESTEI! A PESSOA QUE ME DEU É QUE USA ESSE TIPO DE ROUPA, É A CARA DELA. TIVE A IMPRESSÃO DE QUE ELA COMPROU PRA ELA E POR ALGUM MOTIVO ME DEU COMO PRESENTE DE AMIGO OCULTO (E13).

Essas histórias apresentam uma característica comum: nelas, o doador, ao ofertar um objeto inadequado para uso pelo receptor, expressa uma visão equivocada a seu respeito (no caso do MP3 e da calça) ou uma desatenção para com suas características (no caso do pente). Esses aspectos foram discutidos por Schwartz (1967) como “imposição de identidade”, ou seja, as imagens que os outros fazem de nós em sua mente são transmitidas por meio dos presentes ofertados. A decepção acontece quando a ideia que o receptor evoca na imaginação do doador não condiz com a realidade. Assim, a conhecida expressão "um presente que é a sua cara” (COELHO, 2006, p. 35) dita por um doador pode não ser sempre condizente com a percepção do receptor.

Por outro lado, os consumidores podem também basear suas decisões de compra de presentes na sua própria imagem, conforme discutiram Sherry e McGrath (1989). Isso ficou evidente na pesquisa porque, durante as entrevistas, os entrevistados eram questionados, em momentos diferentes da entrevista, sobre o tipo de presentes que gostam de dar e o tipo de presente que gostam de receber. Muitos respondentes relataram nos dois momentos (dar e receber) o mesmo tipo de produto, ou seja, disseram que costumam presentear com o mesmo tipo de objeto que gostam de ganhar. E2, por exemplo, que gosta de receber vestuário (roupa e moda), também gosta de presentear com esse tipo de produto. E3, que gosta de receber joias, faz o mesmo. Se eles conseguem agradar os seus presenteados, não foi possível descobrir na pesquisa.

Outro elemento relevante que apareceu nas entrevistas foi a ligação que o recebedor do presente faz com a pessoa do doador. É como se o presenteado sentisse necessidade de ver naquele presente recebido a pessoa que o presenteou. $\mathrm{O}$ relato abaixo é bastante significativo nesse sentido.

Uma Amiga me deu um VAle-CD. Eu Detestei. Comprei o CD, MAS NÃO GOSTEI, NÃO ME SENTI À VONTADE COM AQUILO. [POR QUÊ?] PORQUE PARECE QUE... QUANDO VOCÊ RECEBE UM PRESENTE DE UMA PESSOA, UM AMIGO, POR EXEMPLO, VOCÊ SEMPRE LIGA AQuele PRESEnte À PESSOA QUE TE DEU Aquele PRESEnTE. Mas, NESSE CASO, O FATO DE EU TER ESCOLHIDO O PRESENTE, EU ACHO QUE PERDEU UM POUCO ESSA MAGIA, NÉ, OU SEJA, OLHAR PARA O PRESENTE E FAZER O VÍNCULO COM AQUELA PESSOA, PERDEU ESSE VÍNCULO (E7).

É como se o presente carregasse algo da pessoa que deu o presente, como teorizado por Mauss (2003). Com relação a esse aspecto, cabe destacar que duas entrevistadas (E2 e E17) chegam a ponto de ficar com o presente recebido mesmo sabendo que não vão usá-lo.

EU NÃo GOSTO DE TROCAR PRESENTES PORQUE A PESSOA DEU AQUELE PRESENTE E, SE TROCAR, NÃo É MAIS O MESMO. MESMO SE EU NÃO FOR USAR, EU FICO COM ELE, NÃO COSTUMO TROCAR (E2). 
Para Sherry e McGrath (1989), ao selecionar um presente específico, o doador demonstra familiaridade com as preferências do receptor. Quando isso acontece, o presente evoca no receptor uma grande satisfação por não ser convencional, ou seja, por ser personalizado, conforme relata E11.

... UM PRESENTE QUE EU GOSTEI MUITO FOI UMA TORTA DE ABACAXI QUE GANHEI DE UMA AMIGA NO MEU ÚLTIMO ANIVERSÁRIO.

NÃO FOI PELA TORTA EM SI, MAS FOI PORQUE ELA TROCOU O INGREDIENTE PRINCIPAL. A RECEITA ORIGINAL ERA COM MORANGO E ELA, COMO SABE QUE EU ADORO ABACAXI, TROCOU. FIQUEI FELIZ COM ESSE CUIDADO, FOI UM MIMO... (E11).

Por outro lado, quando o doador não demonstra essa familiaridade, o presente pode evocar sentimentos de decepção, ofensa e irritação. No caso de E5, o que parece aborrecê-lo é a frequência com que isso acontece, ou seja, "há mais de 15 anos" de acordo com relato abaixo:

TODO ANO, A EMPRESA EM QUE MINHA MÃE TRABALHA TEM estas festas de Fim de ANO. Minha mãe tá lá há Mais de 15 ANOS. A PROPRIETÁRIA ME DÁ PRESENTE TODO ANO, MAS NUNCA ACERTA. ELA SEMPRE COMPRA ROUPA QUE NUNCA SERVE OU A COR É ARREGAladA... GERALMENTE os PRESENTES DELA EU NÃO USO... O VALOR DO PRESENTE, PARA MIM, NÃO TEM NENHUMA ASSOCIAÇÃO COM O DINHEIRO, MAS COM O ASPECTO DE A PESSOA TE RECONHECER

\section{A RECIPROCIDADE}

Entre os três momentos do ato de presentear: darreceber-retribuir, o que mais intrigou Mauss (2003) foi a retribuição, ou seja, o que faz as pessoas retribuírem o presente recebido. O tema da reciprocidade apareceu de forma significativa nas primeiras entrevistas. Por isso, depois da amostragem teórica realizada, procurou-se explorar esse tema na segunda ida ao campo, perguntando aos entrevistados se e por que eles retribuem os presentes recebidos. Quando indagados sobre quem eles costumam presentear e de quem eles costumam receber presentes, todos os entrevistados citaram, praticamente, as mesmas pessoas. Isto evidencia o caráter da reciprocidade, ou seja, o aspecto de retribuição.

$\mathrm{O}$ ato de presentear, conforme discutido por Mauss (2003), é um constante ciclo de dar-receber-retribuir. O relato abaixo representa muito bem esse ciclo:

EU NÃO COSTUMAVA COMPRAR PRESENTE PRA ELA [UMA AMIGA], MAS ANO PASSADO ELA ME DEU PRESENTE NO MEU
ANIVERSÁRIO, AÍ ESSE ANO, EU DEI PRESENTE PRA ELA TAMBÉM. (...) NÃO DEI PORQUE ELA ME DEU, EU NÃO PRECISAVA RETRIBUIR, MAS AGORA NÓS SOMOS AMIGAS (E14).

...GOSTO, GOSTO MUITO DE DAR PRESENTES E PRINCIPALMENTE PORQUE EU PRECISO RETRIBUIR PORQUE EU RECEBO MUITO (E6).

Tem duas Pessoas Que só ME DÃo PRESENTES SE EU DER PRA ELAS. O ANIVERSÁRIO DELAS É ANTES DO MEU. QUANDO EU DOU PRESENTE PRA ELAS, ELAS ME DÃO. SE EU NÃO DER, ELAS NÃO ME DÃO NADA, FICAM QUIETINHAS. TODO ANO É ASSIM! (E8).

Essas histórias confirmam que liberdade e obrigação se misturam no ritual de presentear. É como descobriu Mauss: a obrigação de dar é acompanhada sempre de duas outras, receber e retribuir. Algumas pessoas afirmam que sabem não precisar retribuir (E14), outras declaram claramente que presenteiam também porque precisam retribuir (E6), mas, de alguma forma, todos acabam retribuindo. Confirma-se assim, que dar, receber e retribuir são temas do mesmo complexo. Portanto, o ato de presentear repousa em um princípio de liberdade e de obrigação estreitamente misturadas.

A explicação para esse sentimento de "obrigação" de retribuir parece estar na manutenção da relação. É como um ciclo: o doador presenteia uma pessoa, essa pessoa retribui o presente recebido, o doador presenteia novamente e a pessoa retribui novamente e, consequentemente, o laço afetivo vai se fortalecendo. Confirma-se, então, que o essencial no ato de presentear é o valor de vínculo, como entendeu Godbout (1999).

Quantos de nós já ouvimos do recebedor do presente a expressão "não precisava, não precisava se incomodar”. Mesmo assim, dificilmente presenciamos alguém indo a uma festa de aniversário, por exemplo, sem levar um presente. Godbout (1999, p. 215) explica muito bem esse comportamento: “afirma-se a ausência de espera de retorno, mas espera-se que a dádiva seja retribuída. Alardeia-se a dádiva, mas fica-se na reciprocidade”. Alguns entrevistados deixaram claro o desejo de serem retribuídos.

FICO MUITO SENTIDA QUANDO ALGUÉM NÃO RETRIBUIU (E4).

Eu GOSTO DE DAR PRESENTE, MAS..., SÓ QUE É 
INTERESSANTE TANTO DAR QUANTO RECEBER. É MAIS INTERESSANTE RECEBER PORQUE VOCÊ FICA NA EXPECTATIVA DO QUE A PESSOA VAI TE DAR (E5).

A reciprocidade é desejada, mesmo quando ela não vem do recebedor, como acontece no amigo oculto. Dois casos relatados evidenciam situações em que a retribuição é considerada inadequada, engendrando ressentimentos. No caso de E13, que se ofendeu por ter recebido um presente que jamais usaria (calça), ela ainda destaca: " $e$ o pior é que eu comprei uma camisa linda e cara para o meu amigo oculto” (E13). E4 é ainda mais categórica: "no amigo oculto, eu caprichei, juntei, juntei dinheiro, gastei pra comprar um presentão e recebi um sabonete... foi frustrante!".

Embora as pessoas afirmem que o objeto é menos importante do que a intenção, elas esperam receber algo de valor equivalente ao que foi dado, ficando irritadas se o presente retribuído não corresponde à expectativa. Dessa forma, não basta retribuir o presente, mas é importante retribuí-lo de modo adequado, conforme afirmou Mauss (2003). As piores situações identificadas nesse sentido ocorreram nos rituais de amigo oculto.

Observa-se que na sociedade contemporânea, assim como nas sociedades tradicionais, os presentes também são, em teoria, voluntários, mas, na realidade, são obrigatoriamente dados e retribuídos, segundo ficou evidenciado nas histórias narradas pelos entrevistados.

\section{O SIMBÓLICO POR EXCELÊNCIA}

Muitos entrevistados classificaram como presentes que marcaram suas vidas pequenos objetos, objetos de baixo ou nenhum valor monetário, mas com grande valor simbólico. Ao relatarem suas histórias, alguns se emocionaram e outros demonstraram saudosismo. Assim, confirma-se o que está evidenciado na literatura: o ato de presentear está extremamente relacionado à dimensão simbólica.

...PRESENTE MARCANTE É O QUE RECEBI QUANDO TINHA 6 ANOS DE IDADE - UM FERRORAMA QUE RECEBI DO MEU AVÔ, TENHO ATÉ HOJE.

TENHO MUITO CARINHO POR ESTE PRESENTE E GUARDO ATÉ HOJE E PRETENDO USÁ-LO COM MEUS FILHOS FUTURAMENTE (E7).

No INÍCIO DO NAMORO, ELE [O NAMORADO] ME DEU UMA GIRAFINHA
DE PELÚCIA, FOI SUPER BONITINHO. EU ACHO QUE O QUE REALMENTE MARCA É A CIRCUNSTÂNCIA, A PESSOA QUE DÁ E NÃO O PRESENTE EM

Os relatos dos entrevistados demonstram ainda que eles valorizam o esforço ou o trabalho despendido pelo presenteador na escolha do presente.

ANTES, NO ANIVERSÁRIO DE QUALQUER UM DOS AMIGOS DA NOSSA TURMA, CADA UM COMPRAVA UM PRESENTE PARA DAR PARA O ANIVERSARIANTE. ERAM PRESENTES BARATINHOS, MAS CADA UM ESCOlhia E DAVA o SEU. Depois, Eles [os Amigos] RESOlVERAM SE UNIR PARA COMPRAR UM PRESENTE MELHOR. ENTÃO, AGORA, EU SEMPRE GANHO UM PRESENTE BOM, CARO, MAS É SEM GRAÇA... EU PREFERIA ANTES (E12).

Esses relatos revelam aspectos da dimensão simbólica do comportamento de presentear. Eles servem para confirmar que o presente ultrapassa a materialidade das coisas. Os presentes marcantes, para a maior parte dos entrevistados, estavam relacionados às pessoas que deram os presentes e não ao valor monetário do presente ou à sua tangibilidade. Os aspectos intangíveis do presente, de acordo com os dados desta pesquisa, parecem ser predominantemente mais importantes do que os aspectos tangíveis.

Uma entrevistada, por exemplo, classificou como o presente mais marcante de sua vida uma festa surpresa que ganhou do marido, conforme relato abaixo. Juntamente com essa festa, ela ganhou uma aliança de ouro branco com diamante. Relatou, entretanto, como presente marcante, a festa, e não a aliança. Assim, mesmo sendo o presente valioso monetariamente, o valor simbólico, a relação que ele representa parece ser mais importante ainda. A entrevistada parece tem valorizado mais a festa do que a joia.

\footnotetext{
O MELHOR PRESENTE DA MINHA VIDA FOI UMA FESTA SURPRESA. EU NUNCA TIVE FESTA DE ANIVERSÁRIO MESMO QUANDO ERA CRIANÇA PORQUE EU VIM DE UMA FAMÍLIA MUITO SIMPLES. QUANDO EU FIZ 26 ANOS, MEU MARIDO ME PRESENTEOU COM UMA FESTA SURPRESA. FoI O PRESENTE MAIS IMPORTANTE, MAIS BONITO DA MINHA VIDA (E4).
}

Eu RECEBI FLORES DA MiNHA NAMORADA. EU ADORO RECEBER FLORES. FoI INESQUecível. SE EU PUDESSE, EU DARIA FLORES TODOS 
OS DIAS, É COMO SE FOSSE UMA JOIA, É COMO SE EU DISSESSE: FIQUE FELIZ HOJE! (E3).

\section{SENHOR E ESCRAVo}

O presentear pode ser encarado também como um ritual torturante - aspecto analisado por Hayden (1987) com base no posicionamento magister (o mestre, o doador) e minister (o escravo, o devedor). As situações, abaixo descritas, demonstram a percepção que algumas pessoas têm do constrangimento que o presente pode causar e como o presenteado se sente devedor do presenteador.

UMA COLEGA DE TRABALHO DISSE QUE QUERIA ME AGRADECER POR TUDO QUE EU TENHO FEITO POR ELA NA EMPRESA E ME DEU UM PRESEnTE, EU ACABEI ACEITANDO. MAS NÃO GOSTEI, NÃO GOSTEI.

Ela tÁ COMO MiNHA SUbORdinAdA E EU ME SENTI ASSIM... COMO SE ELA TIVESSE COMPRANDO A MINHA PARCERIA PORQUE... ELA CHEGA ATRASADA, SAI TODA HORA... NÃO FOI LEGAL, EU TÔ ME SENTIDO DEVEDORA; E NA HORA QUE EU PRECISAR CHAMAR ATENÇÃO DELA? NA HORA DE COBRAR, ESSE PRESENTE, DE CERTA FORMA, PESA (...) TUDO QUE EU FIZ POR ELA, NÃO FOI PORQUE EU SOU BOAZINHA, É PORQUE EU SOU JUSTA. EU FIZ POR TODOS NA EMPRESA E ELA NÃO PRECISAVA ME DAR PRESENTE (E8).

No relato de E1, a seguir, a preocupação não é somente em pagar a dívida, mas também em pagar à altura e, até mesmo nas relações próximas (E5), é possível encontrar o caráter de dívida e da equivalência do ato de presentear.

EU TENHO UM AMIGO QUE É UMA FIGURA, ELE GOSTA DE DAR PRESENTES, GOSTA DE PRESENTEAR COISA CARA, COISA BOA E ELE SEMPRE ME COLOCA EM SITUAÇÃO DIFÍCIL. No MEU ANIVERSÁRIO ELE ME DEU UMA CAMisA do Flamengo OfiCial, 150,00!!! E AGORA, AMANHÃ, É ANIVERSÁRIO DELE E EU VOU TER QUE DAR, PELO MENOS, UMA CAMISA OFICIAL PRA ELE. FUI NA ARgENTINA, “PERDI TEMPO” PORQUE EU QUERIA... COMPREI UMA CAMISA DO BOCA JR. PRA ELE.

MAS FOI MUITO NA OBRIGATORIEDADE, É LÓGICO QUE EU SABIA QUE ELE IA GOSTAR, NÃO FOI TOTALMENTE NO SACRIFÍCIO, MAS FOI NO SENTIDO DE TER UMA OBRIGAÇÃO COM ELE. O ANIVERSÁRIO É Amanhã, mas eU JÁ Dei logo o PRESENTE. Pra matar JÁ A díVIDA

NÃO ME SINTO NA OBRIGAÇÃO DE RETRIBUIR. MAS ACABA Que é nATURAL. A gente [Pessoas DA FAmília] PROCURA DAR NA MESMA MEDIDA EM QUE A GENTE RECEBE (E5).
Esses relatos, além de serem relevantes para evidenciar a posição de devedor que o recebedor assume ao aceitar o presente, revelam também a importância da reciprocidade - categoria discutida anteriormente.

\section{VALE-PRESENTE}

Apesar de Atbay (1993) afirmar que ofertar um valepresente é mais sentimental e ingênuo do que entregar o dinheiro per se, ficou evidente, no decorrer das entrevistas, que as pessoas colocam o vale-presente e o presentear com dinheiro ou cheque em um mesmo patamar. Por isso, esses dois tipos de presente foram inseridos em uma mesma categoria.

Ao se referirem a presentear ou a ser presenteada com vale-presente ou com dinheiro, a maior parte dos entrevistados demonstrou certo repúdio por essa alternativa. Todos os entrevistados contaram uma história de um presente marcante em suas vidas, mas em nenhum dos relatos apareceu o vale-presente ou o presente em dinheiro. Ainterpretação dos dados desta pesquisa revelou, entretanto, que tal rejeição está relacionada com a ocasião e com a pessoa, ou seja, o vale-presente e o presente em dinheiro, em algumas ocasiões e vindos de determinadas pessoas, parecem ser aceitos com tranquilidade.

Teve um [presente em dinheiro] Que Eu gostei (...). QUANDO NÓs [ELE E ESPOSA] ESTÁVAMOS MONTANDO NOSSA CASA, O AVÔ [DA ESPOSA] DEU DINHEIRO PRA GENTE COMPRAR O QUE QUISESSE, NÓS ADORAMOS, COMPRAMOS UMA GELADEIRA (E7).

RECEBI DINHEIRO NO CASAMENTO. EU GOSTEI PORQUE PODIA COMPRAR O QUE QUISESSE PRA CASA (E4).

Minha Mãe Só ME DÁ PRESENTE EM DiNHEIRO. Eu GOSTO PORQUE, NA VERDADE, SE EU FOR ANALISAR, É MUITO MELHOR A PESSOA ESCOLHER O QUE ELA QUER TE DAR, MAS... É O JEITINHO DELA E EU ENTENDO (E6).

Meus avós me DAVAm PRESENTE EM DinheIro E EU ADORAVA (E2).

Em ocasiões como casamento, parece que as pessoas aceitam com facilidade o presente em dinheiro. Mas quando se tratou de um presente pessoal vindo de uma 
pessoa próxima, os entrevistados demonstraram não gostar dessa alternativa.

Uma Amiga me deu um Vale-CD. Eu Detestei. Comprei o CD, MAS NÃO GOSTEI, NÃO ME SENTI À VONTADE COM AQUILO. [POR QUÊ?] Porque PARECE QUE... QUANDO VOCÊ RECEBE UM PRESENTE DE UMA PESSOA, UM AMIGO, POR EXEMPLO, VOCÊ SEMPRE LIGA Aquele PRESENTE À PESSOA QUE TE DEU AQUELE PRESENTE. MAS, NESSE CASO, O FATO DE EU TER ESCOLHIDO O PRESENTE, EU ACHO QUE PERDEU UM POUCO ESSA MAGIA, NÉ, OU SEJA, OLHAR PARA O PRESENTE E FAZER O VÍNCULO COM AQUELA PESSOA, PERDEU ESSE víNCULO (E7).

RECEBER Dinheiro dos Meus PAIS, EU NÃo Ligo. Depende dA PESSOA, MAS SE FOSSE MINHA ESPOSA, UM AMIGO PRÓXIMO, EU NÃO IA ME SENTIR LEGAL. Não É UMA COISA QUE EU GOSTARIa (E1).

EU ACHO QUE DAR PRESENTES EM DINHEIRO PERDE O SENTIDO. Com minha AVÓ ERA Diferente, Já tinha AQUele COSTUME. MaS SE OUTRA PESSOA ME DER, EU NÃO IA GOSTAR NÃO (E15).

DiNHEIRO É DINHEIRO; PRESENTE É PRESENTE, É SURPRESA

Esses relatos reforçam as afirmações encontradas na literatura de marketing de que a ação de presentear é envolvida pelo contexto no qual tanto o presenteador quanto o presenteado estão inseridos (LARSEN; WATSON, 2001).

Assim, a propensão a dar vale-presentes está diretamente relacionada com a proximidade e com a ocasião. É como se, de pessoas próximas, como avós e pais, "tudo é permitido, aceito" porque a relação é simbólica por excelência. Mas quando se trata de namorada, esposa e amigos, as pessoas parecem querer uma prova da importância da relação, ou seja, o esforço, o cuidado na escolha do presente.

Se se adotar, ainda, a concepção de Bourdieu (1996), pode-se afirmar que o vale-presente desobedece a uma regra fundamental do ato de presentear - a regra do implícito -, pois no vale-presente o preço está explícito. Nesta pesquisa, o vale-presente foi considerado, pela maioria dos entrevistados, como a eliminação do aspecto simbólico do presente. Para eles, o vale-presente faz perder a magia e o ritual, o que fica mais evidente ainda na fala de E7 ao se referir ao vale-CD.
Percebeu-se que algumas pessoas enfrentam conflitos no momento de presentear. Alguns entrevistados afirmaram gostar muito de dar presentes, mas, ao mesmo tempo, sentir-se angustiados devido à falta de tempo para escolher o presente adequado, razão porque fazem uso, às vezes, da alternativa do vale-presente. $\mathrm{O}$ relato abaixo evidencia outro tipo de conflito vivenciado pelo esposo, que adora presentear a esposa, mas, tendo dificuldade de escolher o presente certo, decide presentear com dinheiro. Mas veja-se o que acontece:

Meu marido, no ano PASSAdo, ME deU PRESEnte NO MEU ANIVERSÁRIO. QUERIA ME AGRADAR; COMO ELE SABE QUE EU SOU DIFÍCIL, ELE COMPROU TRÊS PRESENTES EM TRÊS LOJAS DIFERENTES. MAS NENHUM DOS TRÊS DEU CERTO E EU NÃO SEI FINGIR QUE GOSTEI. Neste ANO, Ele RESOlVEU ME DAR Dinheiro (...), MAS EU NÃO GOSTEI, FOI PIOR AINDA (E8).

Grande parte dos entrevistados não demonstrou propensão a dar vale-presentes, a maioria deles disse preferir ir à loja, por exemplo, com a pessoa a ser presenteada a dar um vale-presente. Outros, contudo, relataram situações em que o vale-presente pode ser uma opção interessante. Uma entrevistada, por exemplo, relatou que pretende dar um vale-presente para sua afilhada porque "ela é adolescente e, por isso, é difícil de agradar” (E11). Essa situação confirma o resultado de Santana, Carvalho e Fagundes (2006) ao evidenciarem que as pessoas fazem uso do vale-presente para presentear pessoas difíceis. Entretanto, conforme pode ser observado no relato de E8, isso nem sempre representa a solução.

E15 relatou que no aniversário do seu chefe deu valepresente porque não conhecia seu gosto, e E14 afirmou: "sempre dou vale-presente quando se trata de colegas de trabalho”. Essas situações sugerem que, quando a relação entre duas pessoas não é muito próxima, o vale-presente pode ser uma alternativa desejável. Assim, mais uma vez, confirma-se que a ação de presentear é envolvida pelo contexto no qual tanto o presenteador quanto o presenteado estão inseridos (LARSEN; WATSON, 2001).

\section{Considerações Finais}

Este trabalho teve como objetivo conhecer o que o consumidor tem a dizer a respeito de suas experiências de dar e receber presentes. Verificando o surgimento 
de um novo formato de presentear - o vale-presente -, buscou-se resposta para as seguintes questões: o ato de presentear ainda carrega predominantemente dimensões simbólicas? A crescente utilização do vale-presente indica uma tendência de redução do simbolismo do ato de presentear?

A metodologia utilizada foi a grounded theory. Por meio desse método, extraíram-se e desenvolveramse quatro categorias, que revelaram aspectos bastante relevantes sobre o comportamento de presentear. Elas respondem, em seu conjunto, as questões desta pesquisa, evidenciando que o ato de presentear continua tendo essencialmente uma aura de simbolismo, cujo valor simbólico perdura na sociedade contemporânea, ainda que sejam aceitas alternativas mais utilitaristas.

O vale-presente, por sua vez, mesmo não tendo boa aceitação entre a maioria dos entrevistados, foi considerado apropriado para determinados contextos de baixa intimidade e nas relações entre pais e filhos. Muitas empresas, no entanto, estão procurando incrementar o vale-presente, sugerindo aos consumidores que o ofertem juntamente com caixas de bombons ou buquês de flores, para minimizar a rejeição a esse tipo de compra. Isso evidencia uma tentativa de fazer com que a dimensão simbólica esteja presente, mesmo com a utilização de formas alternativas.

A diversidade de situações que motivam o ato de presentear deve ser analisada pelas empresas, pois a opção do vale-presente deve ser posicionada de formas diferentes a fim de potencializar o seu uso. A dimensão econômico-funcional e a redução de riscos podem ser destacadas em determinadas situações “paternalistas” ou de baixa intimidade, enquanto a associação com flores e outros presentes pode ser estimulada para diminuir a rejeição dos receptores.

Quanto às futuras pesquisas, sugerem-se estudos que considerem o fator tempo, o qual apareceu como limitante para o ato de presentear. A maior parte das pessoas revelou que gosta de dar presentes ou que adora fazê-lo. Contudo, muitos dos participantes alegaram não ter tempo para escolher presentes e outros disseram ficar angustiadas com isso. Assim, o ato de presentear comumente um ritual considerado relaxante e prazeroso parece, em alguns casos, ser também torturante, conforme já apontara Wooten (2000). Ao mesmo tempo que as pessoas manifestam o desejo de escolher seus presentes de forma a agradar as pessoas que amam, elas revelam angústia por não ter tempo livre para fazê-lo. Poder-se-ia imaginar que o vale-presente seria uma solução a essa falta de tempo, contudo as pessoas parecem não querer fazer uso intensivo dessa alternativa.

Evidencia-se, portanto, a necessidade de realizar pesquisas não só para analisar o ato de presentear, mas também para investigar as consequências que a vida moderna traz para o consumo e, consequentemente, para o marketing. Talvez as empresas possam elaborar mais apropriadamente suas estratégias mercadológicas se compreenderem melhor os conflitos que a vida moderna impõe às pessoas. Portanto, em termos gerenciais, o trabalho contribui com a identificação de que o aspecto tempo tem especial relevância na escolha de um presente, o que ressalta a dimensão da conveniência no varejo físico ou virtual como um elemento importante de decisão.

Outro aspecto a ser investigado seria a influência dos valores culturais no comportamento de presentear, como fizeram Qian, Razzaque e Keng (2007) na China. Por viver o consumidor numa sociedade, os atos dele são por ela influenciados. Dessa forma, as características culturais do meio afetam os hábitos do indivíduo.

Tendo em vista o crescimento do vale-presente no Brasil, conforme divulgado pela mídia televisiva e pelo Portal Varejista (2008), destaca-se a necessidade da realização de mais pesquisas sobre o tema em outros contextos. As categorias identificadas neste estudo constituem um ponto de partida importante para a construção de uma escala que permita quantificar as dimensões do ato de presentear, que possa ser utilizada e validada em estudos subsequentes sobre o tema e que possibilite o aprofundamento de questões não tratadas aqui, como a identificação de segmentos de consumidores com características diferenciadas no que se refere a essa questão. Outro questionamento importante a ser respondido em estudos subsequentes é o seguinte: quais as características demográficas e psicográficas das pessoas que presenteiam com vale-presente?

Os resultados contribuem com elementos teóricos da antropologia para um melhor entendimento do comportamento de presentear. Assim, a relevância deste estudo reside também no aprofundamento da interdisciplinaridade no estudo do comportamento do 
consumidor. Diversos pesquisadores no campo dos estudos organizacionais estão cada vez mais preocupados em explorar os significados construídos e as experiências vividas pelas pessoas, o que tem incentivado também os pesquisadores da área de marketing a buscar soluções alternativas capazes de lançar mão de teoriasmetodologias complementares que permitam lidar com as ambiguidades, a fluidez e as contradições da "vida real". Portanto, acredita-se que a grounded theory tem grande importância nesse sentido, por permitir aos pesquisadores se voltarem para a "realidade" dos sujeitos pesquisados e se aproximarem dela.

Ressalta-se, por fim, que o fato de a pesquisa ter sido realizada em duas cidades do interior também é relevante, tendo em vista a carência de estudos de marketing fora dos grandes centros. Pesquisas semelhantes em outras regiões e em cidades de porte diverso também são sugestões para a agenda de pesquisa.

\section{Notas:}

1 Obra clássica do antropólogo francês Marcel Mauss sobre as trocas nas sociedades tradicionais, escrita em 1923, mas a edição utilizada neste trabalho é de 2003.

${ }^{2}$ Quando se fala de uma teoria que emerge dos dados está-se falando de uma teoria substantiva (GLASER; STRAUSS (1967) que procura refletir a complexidade da vida social. Este tipo de teoria é uma teoria específica, limitada em seu escopo, rica em detalhes e aplicável apenas dentro dos limites de um dado contexto social. Sem a preocupação de generalização estatística para além da sua área substantiva, procura aprofundar a explicação de uma "realidade" local, particular, construída a partir das experiências vividas por um determinado grupo social (DEY, 1999; GOULDING, 2002).

\section{REFERÊNCIAS}

ALMEIDA, A. R. D. de; LIMA, C. Ai meu Deus, o que eu Compro? Um Estudo Experimental sobre a Ansiedade na Compra de Presentes. In: ENCONTRO ANUAL DA ASSOCIAÇÃO NACIONAL DE PÓS-GRADUAÇÃO E PESQUISA EM ADMINISTRAÇÃO, 31, 2007, Rio de Janeiro. Anais do XXXI ENANPAD. Rio de Janeiro: ANPAD, 2007.

ATBAY, S. Giving and getting. American demographics. Nova Iorque: v. 15, n. 12, p. 46-54, dez. 1993.

BELK, R. W. Gift-giving behavior. Research in Marketing. 2 ed. Jagdish N. Sheth, Greenwich, CT: JAI Press, p. 95-126, 1979.

BELK, R. W.; COON, G. S. Gift giving as agarics love: an alternative to the exchange paradigm based on dating experiences. Journal of Consumer Research, v. 20, p. 393-417, dez. 1993.

BOURDIEU, P. Razões práticas: sobre a teoria da ação. Campinas, SP: Papirus, 1996.

CHARMAZ, K. Constructing grounded theory: a practical guide through qualitative analysis. London: Sage Publications, 2006.

COELHO, M. C. O valor das intenções: dádiva, emoção e identidade. Rio de Janeiro: FGV, 2006. 108 p.

DEY, I. Grounding Grounded Theory: guidelines for qualitative inquiry. San Diego, USA: Academic Press, 1999.

FARIAS, S. A. de; DIAS, C. de M.; BENEVIDES, V. M. F.; FERREIRA, P. G. G.; BEZERRA, L. E. de F. O Comportamento de Presentear: Dimensões Motivacionais Relevantes para o Marketing. In: ENCONTRO ANUAL DA ASSOCIAÇÃO NACIONAL DE PÓSGRADUAÇÃO E PESQUISA EM ADMINISTRAÇÃO, 25, 2001, Campinas. Anais do XXV ENANPAD. Campinas/SP: ANPAD, 2001, CD-ROM.

GLASER, B.; STRAUSS, A. The Discovery of Grounded Theory: Strategies for qualitative research. New York: Aldine, 1967.

GODBOUT, J. T. O espírito da dádiva. Em colaboração com Alain Caillé. Rio de Janeiro: Editora Fundação Getúlio Vargas, 1999. 272 p. 
GOULDING, C. Grounded Theory: A Magical Formula or a Potential Nightmare. Marketing Review, vol. 2 (1), p. 21-33 (13), 2001. <http://dx.doi. org/10.1362/1469347012569409>

GOULDING, C. Grounded Theory: a practical guide for management, business and market researchers. London: Sage Publications, 2002.

GOULDNER, A. W. The norm of reciprocity: a preliminary statement. American Sociological Review, Washington, v. 25, n. 2, p. 161-178, Apr. 1960. <http:// www.jstor.org/stable/pdfplus/2092623.pdf>

LARSEN, D.; WATSON, J. J. A guide map to the terrain of gift value. Psychology and Marketing. Auburn, AL: v. 18, n. 8, p. 889-906, ago. 2001. <http://dx.doi. org/10.1002/mar.1034>

MAUSS, M. Ensaio sobre a dádiva: forma e razão da troca nas sociedades arcaicas. In: Sociologia e Antropologia. São Paulo: Cosac \& Naify, 2003, p. 185-314.

MACKLIN, N. C.; WALKER, M. "The joy and irritation of gift-giving”, Proceeding of the Academy of Marketing Science. Academy of Marketing Science, Montreal, 1988, p. 67-86.

MONEY, A. Material culture and the living room: the appropriation and use of goods in everyday life. Journal of Consumer Culture, v. 7, n. 3, p. 355-377, 2007. <http://dx.doi.org/10.1177/1469540507081630>

OTNES, C.; LOWREY, T. M.; KIM, Y. C. Gift selection for easy and difficult recipients: a social roles interpretation. Journal of Consumer Research, Chicago, v. 20, n. 2. p. 229-243. Set. 1993. <http://dx.doi.org/10.1086/209345>

PÉPECE, O. M. C; MARCHETTI, R. Z.; PRADO. Aspectos Sociodemográficos e Culturais Relacionados a Compra de Presentes: Implicações para o Varejo Especializado. In: ENCONTRO ANUAL DA ASSOCIAÇÃO NACIONAL DE PÓS-GRADUAÇÃO E PESQUISA EM ADMINISTRAÇÃO, 25, 2001, Campinas. Anais do XXV ENANPAD. Campinas/SP:
ANPAD, 2001, CD-ROM.

PÉPECE, O. M. C. O Comportamento de Compra de Presentes: mais um simples Ato de Consumo ou uma Forma de Expressão de Significados? In: ENCONTRO ANUAL DA ASSOCIAÇÃO NACIONAL DE PÓSGRADUAÇÃO E PESQUISA EM ADMINISTRAÇÃO, 26, 2002, Salvador. Anais do XXVI ENANPAD. Salvador/BA: ANPAD, 2002, CD-ROM.

PORTAL EXAME. Varejistas dos EUA fazem promoções para melhorar vendas. Disponível em $<$ www.portalexame.abril.com.br $>$. Acesso em: 28 jan. 2008.

PORTAL VAREJISTA. Disponível em <www. portalvarejista.com.br>. Acesso em: 28 jan. 2008.

QIAN, W.; RAZZAQUE, M. A.; KENG, K. A. Chinese cultural values and gift-giving behavior. Journal of Consumer Marketing, 24/4 (2007) 214-228. <http:// dx.doi.org/10.1108/07363760710756002>

SANTANA, E. de P.; CARVALHO, D. T.; FAGUNDES, A. A. Para Quem é o Presente? A Influência dos Papéis Sociais na Propensão de se Dar Vale-presentes. In: ENCONTRO DE MARKETING DA ANPAD, 2, Rio de Janeiro. Anais do II ANPAD. Rio de Janeiro: ANPAD, 2006.

SCHWARTZ, B. The social psychology of the gift. American Journal of Sociology, Chicago, v. 73, n. 1, p. 1-11, 1967. <http://www.jstor.org/stable/ pdfplus/2776124.pdf>

SHERRY, J. F.; McGRATH, M. A. Unpacking the holiday presence: a comparative ethnography of two gift stories. Interpretive Consumer Research, p. 148-167, 1989. <http://www.acrwebsite.org/search/view-conferenceproceedings.aspx?Id=12182>

SHERRY, J. F, Jr. Gift-giving in anthropological perspective. Journal of Consumer Research, v. 10, p. 157-168, Sept. 1983. <http://www.nd.edu/ jsherry/ pdf/1983/Gift\%20Giving.pdf> 
SILVA, C. L.; CERCHIARO, I. B.; MASCETTI, I. Consumo como espiritualidade e consumo do luxo: o que o consumidor tem a dizer? In: ENCONTRO ANUAL DA ASSOCIAÇÃO NACIONAL DE PÓS-GRADUAÇÃO E PESQUISA EM ADMINISTRAÇÃO, 28, 2004, Curitiba. Anais do XXVII ENANPAD. Curitiba/PR: ANPAD, 2004, CD-ROM.

SMART, A. Gifts, Bribes and Guanxi: A Reconsideration of Bourdieu's Social Capital. Cultural Anthropology, v. 8, n. 3, Ago. 1993, p. 388-408. <http://dx.doi.org/10.1525/ can.1993.8.3.02a00060>

STRAUSS, A.; CORBIN, J. Basics of Qualitative Research: Grounded theory procedures and techniques. Newbury Park, CA: Sage Publications, 1998.

TRENTMANN, F. Crossing divides: consumption and globalization in history. Journal of Consumer Culture. v. 9, n. 2, p.187-220, 2009. <http://dx.doi. org/10.1177/1469540509104374>

WOLFINBARGER, M. F. Motivations and Symbolism in gift-Giving Behavior. Advances in Consumer Research, v. 17, p. 699-706, 1990. <http://www.acrwebsite.org/ search/view-conference-proceedings.aspx?Id=7087>

WOLFINBARGER, M. F.; GILLY, M. C. An experimental investigation of self-symbolism in gifts. Advances in Consumer Research, v. 23, p. 458-462, 1996. < http://www.acrwebsite.org/search/view-conferenceproceedings.aspx?Id=7873>

WOOTEN, D. B. Qualitative steps toward an expanded model of anxiety in gift-giving. Journal of Consumer Resource, v. 27, p. 84-95, June 2000. 